\section{ABCS}

How to cite this article: Silva et al. Bruxism in children and adolescents with cerebral palsy. ABCS Health Sci. 2021;46:e021308. https:// doi.org/10.7322/abcshs.2020110.1564

Received: Jul 10, 2020

Revised: Nov 19, 2020

Approved: Dec 08, 2020

Corresponding author: Thyciana Rodrigues Ribeiro - Universidade Federal do Ceará Rua Monsenhor Furtado S/N - Rodolfo Teófilo - CEP: 60430-350 - Fortaleza (CE), Brazil -

E-mail: thyciana_odonto@yahoo.com.br

Declaration of interests: nothing to declare

This is an open access article distributed under the terms of the Creative Commons Attribution License

(C) 2021 The authors

\title{
Bruxism in children and adolescents with cerebral palsy
}

\author{
Sara Maria Silva ${ }^{1}$, Renata Asfor Rocha Carvalho Martins ${ }^{1}$, Thyciana Rodrigues Ribeiro ${ }^{1}$ \\ ${ }^{1}$ Departamento de Clínica Odontológica, Faculdade de Odontologia, Universidade Federal do Ceará \\ (UFC) - Fortaleza (CE), Brazil
}

\begin{abstract}
This study aims to summarize the existing evidence from primary studies in order to answer the following question: "are children and adolescents with cerebral palsy (CP) frequently affected by bruxism?”. For such, databases Web of Science, Medline (via PubMed), Lilacs, SciELO, Scopus and Wiley Online Library were used, with the keywords "Cerebral Palsy" and "Bruxism" alone and in combination, without the restriction of the publication date. The search included all articles published until May 2020. A total of 229 publications were found, of which 12 were selected, after careful analysis. Retrospective data analyses, cross-sectional studies and observational casecontrol studies published in English and with samples composed of children and/or adolescents were included. Case reports, literature reviews and studies whose sample consisted of adults-only were excluded. In the evaluated studies, bruxism was present in all samples with cerebral palsy. However, oral signs and symptoms resulting from this parafunction were reported only in three studies, in which the presence of dental wear and pain was evaluated. Therefore, bruxism in children and adolescents with cerebral palsy is a frequent oral condition, however, knowledge about the associated and risk factors for the occurrence of this problem in these patients remains limited.
\end{abstract}

Keywords: bruxism; Cerebral Palsy; child; Adolescent; prevalence; oral health.

\section{INTRODUCTION}

Cerebral Palsy (CP) describes a group of permanent disorders of movement and posture development ${ }^{1-3}$. This condition has an estimated worldwide prevalence of 2 to 3 cases per 1,000 children and is considered the most common cause of severe physical disability in childhood ${ }^{1,3}$.

The etiology of $\mathrm{CP}$ involves neurological damage during fetal or infant development and, depending on the affected area, it determines different clinical types ${ }^{4-8}$. The spastic form, which accounts for most cases, results from a lesion in the pyramidal system and is predominantly characterized by the presence of elevated tone, hyperreflexia, and spasticity ${ }^{4,5}$. Dyskinetic or athetoid cerebral palsy results from a lesion in the extrapyramidal system, mainly in the basal ganglia, and is commonly characterized by hypotonia, slow and contorted movements, abnormal postural control, motor coordination problems, and oromotor dysfunction ${ }^{7}$. Finally, ataxic cerebral palsy results from a dysfunction in the cerebellum and is characterized by difficulties in voluntary movements, balance, and depth perception, as well as unsteady gait ${ }^{7}$.

It is worth mentioning that some individuals present a combination of motor alterations that are difficult to categorize. These cases are classified as mixed cerebral palsy 5 . Furthermore, the spastic form can also be subdivided into monoplegia (affecting only one 
of the four limbs), tetraplegia (involving all four limbs), diplegia (involving all four limbs, with the upper limbs more affected), and hemiplegia (only one side of the body affected) 7 .

Sleep and awake bruxism are muscular masticatory activities that occur during sleep (characterized as rhythmic or non-rhythmic) and while waked-up (characterized by repetitive or sustained tooth contact and/or jaw immobilization), respectively ${ }^{8}$. The etiology and neurological mechanism of this oral condition are not yet fully understood, but studies point to different associated risk indicators, such as local, psychological, genetic, neurological, systemic, and social factors ${ }^{8-12}$.

In people with cerebral palsy, whose neurological maturation is delayed or non- existent, the presence of parafunctional habits, such as bruxism, has been commonly reported ${ }^{1,3,5,10,13-16}$. Thus, the present study assumes that there is a high prevalence of bruxism in children and adolescents with CP.

Therefore, the purpose of this review was to summarize the existing evidence from primary studies in order to answer the following question, "are children and adolescents with CP frequently affected by bruxism?”.

\section{METHODS}

This is a narrative literature review study. The search for articles included the electronic databases Web of Science - Core Collection, Medline (via PubMed), Lilacs, SciELO, Scopus, and Wiley Online Library. The search included all articles published until May 2020.

Additionally, to compose the search strategy, the keywords bruxism and cerebral palsy from Medical Subject Headings $(\mathrm{MeSH})$ were used. The search used the keywords alone and in combination with the Boolean operator "AND" (bruxism AND cerebral palsy). Finally, after removing duplicate articles, the titles and abstracts were evaluated and, after applying the pre-defined inclusion criteria, the eligible texts were read in full.

Studies published in English, whose sample included children and/or adolescents diagnosed with any type of $\mathrm{CP}$ as a primary disability and that may or may not have associated intellectual or sensory disabilities were considered eligible. The condition bruxism could not be listed as a criterion for the inclusion of the participant in the study. Finally, retrospective analyses of medical record data, cross-sectional observational studies, and observational casecontrol studies were included in this review. Case series and case reports, literature reviews, and observational case-control studies whose sample consisted only of adults were excluded.

\section{RESULTS}

Initially, 229 publications were obtained from the consulted electronic databases. After removing the duplicates, the titles, and abstracts of 173 articles were read and 12 potentially relevant studies were identified for reading in full. The 12 studies were considered eligible for this literature review, as shown in Figure 1.

A retrospective analysis of medical record data was selected according to Souza et al. ${ }^{17}$, eight cross-sectional observational studies, Abanto et al. ${ }^{1}$, Ortega et al. ${ }^{2}$, Castinho et al. ${ }^{3}$, Lindqvist e Heijbel ${ }^{13}$, Peres et al. ${ }^{14}$, Elsayed et al. ${ }^{15}$, Edvinsson e Lundqvist ${ }^{18}$ and Rodríguez et al. ${ }^{19}$, as well as three observational case-control studies, Ortega et al. ${ }^{5}$, Miamoto et al. ${ }^{10}$ and Du et al. ${ }^{20}$.

The 12 studies included were from Egypt: Elsayed et al. ${ }^{15}$, México: Rodríguez et al. ${ }^{19}$, Sweden: Lindqvist e Heijbel ${ }^{13}$ and Edvinsson e Lindqvist ${ }^{18}$, China: Du et al..$^{20}$ and predominantly from Brazil: Abanto et al. ${ }^{1}$, Ortega et al. ${ }^{2}$, Castinho et al. ${ }^{3}$, Ortega et al. ${ }^{5}$, Miamoto et al. ${ }^{10}$, Peres et al. ${ }^{14}$ and Souza et al. ${ }^{17}$. Among the selected articles, a sample of 1,310 individuals with cerebral palsy was obtained.

Lindvisq e Heijbel ${ }^{13}$ and Du et al. ${ }^{20}$ investigated the presence of bruxism based on the degree of tooth wear, determined by recording enamel and dentin veneers on permanent teeth ${ }^{21}$. In the study by Peres et al. ${ }^{14}$, the diagnosis of bruxism was determined based on the observation of the caregiver (audible occlusal sounds indicating the presence of the parafunction) and on the clinical oral examination based on Genon's methodology ${ }^{22}$, in which the presence of wear facets is observed. Miamoto et al. ${ }^{10}$ also considered the report of a third person and the clinical oral examination to determine the diagnosis of bruxism. In this case, reports of grinding noises (at least three times per week) and the presence of shiny and polished veneers on the permanent incisors and/or first molars (mainly on the palatal surface and incisal edges and working cusps, respectively), considering the time of the eruption. Abanto et al. ${ }^{1}$, Elsayed et al. ${ }^{15}$ and Rodríguez et al. ${ }^{19}$ determined the diagnosis of bruxism

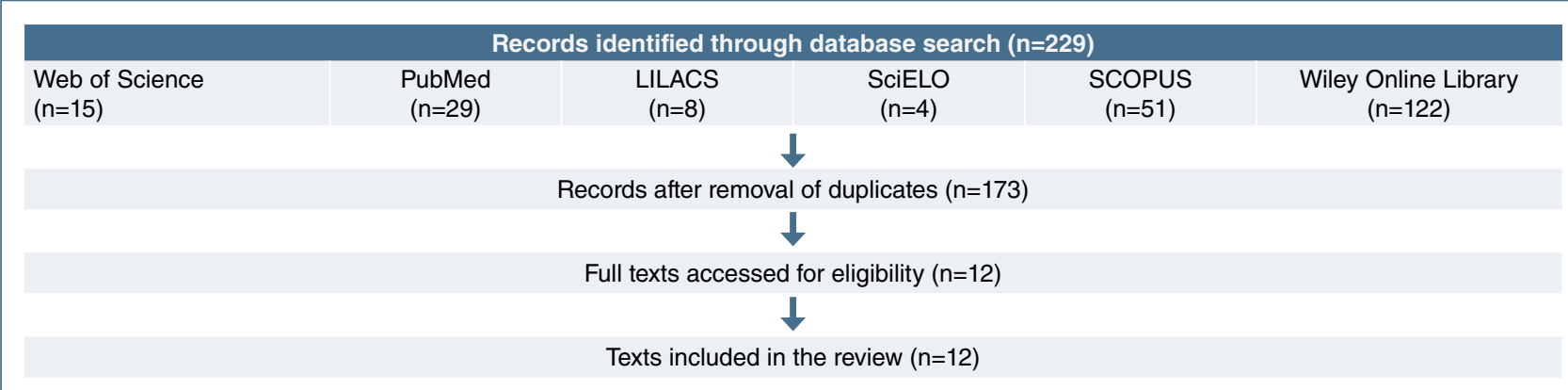

Figure 1: Flowchart - Article Selection Process. 
based on the caregiver's report and the tooth wear observed during the clinical oral examination. Ortega et al. ${ }^{2}$, Castinho et al. ${ }^{3}$, Ortega et al. ${ }^{5}$, Souza et al. ${ }^{17}$ and Edvinsson e Lindqvist ${ }^{18}$ determined the presence of bruxism only based on the report of the person who was necessarily with the patient most of the time, including during sleeping hours, and any involuntary activity of the masticatory muscles that resulted in teeth grinding was considered bruxism.

Lindqvist e Heijbel ${ }^{13}$, Peres et al. ${ }^{14}$, Elsayed et al. ${ }^{15}$, Souza et al. ${ }^{17}$, Edvinsson e Lindqvist ${ }^{18}$, Rodríguez et al. ${ }^{19}$ and $\mathrm{Du}$ et al. ${ }^{20}$ evaluated patients with different types of CP. Whereas, Abanto et al. ${ }^{1}$, Ortega et al. ${ }^{2}$, Castinho et al. ${ }^{3}$, Ortega et al. ${ }^{5}$ and Miamoto et al. ${ }^{10}$ included only patients with spastic CP. Peres et al. ${ }^{14}$ excluded children with gastroesophageal reflux, because according to Shaw et $\mathrm{al}^{23}$, this condition contributes to tooth erosion and maybe the most important factor in the etiology of tooth wear rather than parafunctional activity. Finally, not having previously undergone any type of orthodontic intervention was also mentioned as an inclusion criterion by Miamoto et al. ${ }^{10}$.

Bruxism was present in a higher or lower percentage in the patients with CP of all the samples of the studies included in this review, as shown in Table 1 . This finding suggests that cerebral palsy is an important risk factor for bruxism. Peres et al. ${ }^{14}$ also observed that children with spastic quadriplegia and athetosis subtypes had higher rates of bruxism than children with other types of cerebral palsy $(\mathrm{p}<0.05)$. Furthermore, according to Lindqvist and Heijbel ${ }^{13}$, patients with a lower level of development, that is, with $\mathrm{CP}$ of greater severity, had a statistically higher number of children with abnormal dental wear than in the other groups ( $\mathrm{p}<0.001$ ), indicating a relationship between bruxism and the degree of severity of cerebral palsy.

\section{DISCUSSION}

Bruxism brings several complications to the affected individual depending on the intensity and frequency of this habit ${ }^{7}$. Unfortunately, parafunctional movements such as this have been commonly observed in children and adolescents with cerebral palsy and have even been mentioned by some scholars as a characteristic inherent to $\mathrm{CP}^{14,20}$.

Tooth enamel is the first structure to receive the parafunctional load of bruxism ${ }^{24}$. The loss of tooth tissue caused by this condition can result in sensitivity, excessive height reduction of the clinical crown and changes in the occlusal relationship ${ }^{25-27}$. Moreover, according to Bahlis et al. ${ }^{28}$, the clinical manifestations most associated with bruxism are non-functional patterns of tooth wear, abfractions, fractures and restorations, increased tone and hypertrophy of the masticatory muscles, headache, temporomandibular joint symptoms, dental pain and periodontal and endodontic implications.

Several factors may explain the origin of bruxism in children and adolescents with cerebral palsy. Among them are the spasticity; oral myofunctional disorders; dysfunctions in the posterior bones of the head, which is projected anteriorly, modifying the dental contact and predisposing the individual to a hyperactivity of the temporal

Table 1: Summary of the articles regarding the presence of bruxism.

\begin{tabular}{|c|c|c|c|c|c|c|c|}
\hline \multirow{2}{*}{ Author/Year } & \multirow{2}{*}{$\mathbf{N}$} & \multirow{2}{*}{ CP } & \multirow{2}{*}{ Age } & \multirow{2}{*}{$\mathrm{M} / \mathrm{F}$} & \multicolumn{3}{|c|}{ Bruxism } \\
\hline & & & & & N/type & Age group (\%) & Sex \\
\hline \multirow{2}{*}{ Lindqvist \& Heijbel, $1974^{13}$} & 17 & $\mathrm{E}$ & \multirow{2}{*}{ NR } & \multirow{2}{*}{ NR } & $1 / \mathrm{SA}$ & \multirow{2}{*}{ NR } & \multirow{2}{*}{ NR } \\
\hline & 10 & NE & & & $4 / \mathrm{SA}$ & & \\
\hline \multirow{2}{*}{ Peres et al. $2007^{14}$} & 100 & $E$ & \multirow{2}{*}{$4-7$} & \multirow{2}{*}{$67 / 54$} & 67/SA & \multirow{2}{*}{$\begin{array}{l}4-5(54.4) \\
6-7(77.3)\end{array}$} & \multirow{2}{*}{ NR } \\
\hline & 21 & $\mathrm{NE}$ & & & $17 / S A$ & & \\
\hline Ortega et al. $2007^{5}$ & 65 & $E$ & $2-20$ & $38 / 27$ & $24 / S A$ & $\begin{array}{c}2-6(50.0) \\
7-11(36.3) \\
12-16(33.3) \\
17-20(14.2)\end{array}$ & NR \\
\hline \multirow{2}{*}{ Du et al. $2010^{20}$} & 44 & $E$ & \multirow{2}{*}{$2,5-6,4$} & \multirow{2}{*}{$39 / 33$} & \multirow{2}{*}{$45 / \mathrm{SA}$} & \multirow{2}{*}{ NR } & \multirow{2}{*}{ NR } \\
\hline & 28 & $\mathrm{NE}$ & & & & & \\
\hline Miamoto et al. $2011^{10}$ & 60 & NR & $\geq 3$ & $28 / 32$ & $14 / S$ & $\begin{array}{l}>10(26.7) \\
\leq 10(20.0)\end{array}$ & NS \\
\hline Abanto et al. $2013^{1}$ & 60 & $\mathrm{E}$ & $6-14$ & $30 / 30$ & $31 / \mathrm{SA}$ & NR & NR \\
\hline \multirow{2}{*}{ Elsayed et al. $2013^{15}$} & 65 & $E$ & \multirow{2}{*}{$2-12$} & \multirow{2}{*}{$48 / 52$} & \multirow{2}{*}{$38 / \mathrm{S}$} & $2-5(50.0)$ * & \multirow{2}{*}{ NR } \\
\hline & 35 & NE & & & & $6-12(25.0)$ & \\
\hline Ortega et al. $2014^{2}$ & 137 & NR & $2-18$ & $67 / 70$ & $\begin{array}{c}9 / \mathrm{A} \\
24 / \mathrm{S} \\
54 / \mathrm{SA}\end{array}$ & NR & $\mathrm{M}^{*}$ \\
\hline \multirow{2}{*}{ Souza et al. $2015^{17}$} & 227 & $E$ & \multirow{2}{*}{$1-13$} & \multirow{2}{*}{ NR } & $91 / \mathrm{S}$ & \multirow{2}{*}{ NR } & \multirow{2}{*}{$M^{*}$} \\
\hline & 43 & NE & & & 9/S & & \\
\hline \multirow{2}{*}{ Edvinsson \& Lundqvist, $2016^{18}$} & 87 & $E$ & \multirow{2}{*}{$5-22$} & \multirow{2}{*}{$76 / 53$} & $23 / 4$ & $\mathrm{NR}$ & $\mathrm{NR}$ \\
\hline & 42 & NE & & & $\angle \mathrm{O} / \mathrm{A}$ & TI & T) \\
\hline Castinho et al. $2017^{3}$ & 149 & $E$ & $1-13$ & $0 / 149$ & 44/SA & $\leq 3(57.7)$ & NR \\
\hline Rodríquez et al $2018^{19}$ & 75 & $E$ & $9-44$ & $64 / 56$ & $12 / \mathrm{SA}$ & NR & NR \\
\hline & 45 & NE & $y-44$ & $64 / 56$ & & & \\
\hline
\end{tabular}

M: male. F: female. CP: cerebral palsy. NR: not reported. NS: statistically non-significant difference. S: sleep bruxism. A: awake bruxism. SA: sleep and awake bruxism. ${ }^{\star} \mathrm{p}<0.05$ 
and masseter muscles; the reduction of the mandibular posture control that can worsen in periods of emotional stress; the sleep disorders and the use of neuroleptics ${ }^{6,10,14}$. This parafunction seems to be modulated by several neurotransmitters of the central nervous system, involving disturbances in the mechanism of dopaminergic function ${ }^{5,16}$. Considering that cerebral palsy also presents a disorder of this same dopaminergic ${ }^{5,16}$, system, it could explain the high frequency of this parafunction in these patients.

When evaluating the behavior of the affected individuals by age range, there was a decrease in the occurrence of bruxism, coinciding with the increase in age. However, bruxism did not cease completely over time, which suggests that the maturation of the central nervous system, although limited in people with CP, would allow its decrease, but not absence, because it involves a larger amount of determining factors ${ }^{3,10,14-16}$.

As for the variable sex, two studies pointed out a higher prevalence for males ${ }^{2,17}$. However, there are not enough arguments to support the association between bruxism and the variable sex.

It is also observed that some studies mention neuroleptic drugs, frequently used by individuals with $\mathrm{CP}$, as possible contributors to the etiology of bruxism in this group ${ }^{13,16,17}$. However, for Ortega et al. ${ }^{2}$, there is no statistically significant difference in relation to this aspect.

Additionally, experimental studies on bruxism therapy have been conducted. However, what works for individuals without CP may not be adequate for people with that condition. The dental approach to this parafunction in children without comorbidities can be questioned, sometimes preferring behavioral approaches conducted by speech therapy, physical therapy, and psychology teams, as observed by Ilovar et al. ${ }^{29}$, Gomes et al. ${ }^{30}$, Amorim et al..$^{31}$ and Beddis et al. ${ }^{32}$. There is still no proven effective therapy for this parafunction in individuals with CP. Oliveira et al. ${ }^{33}$ reported the control of bruxism in a child through the use of an acrylic resin protective appliance fixed on both sides of the mandible. Giannasi et al. ${ }^{34}$ reported the beneficial effect of a hyperboloid chewing appliance for the treatment of severe sleep bruxism in a child. Manzano et al. ${ }^{35}$, Kesikburun et al. ${ }^{36}$ and Cahlin et al..$^{37}$, on the other hand, deal with the use of botulinum toxin type $\mathrm{A}$ in the treatment of this parafunction. But, among other limitations, these studies do not have representative samples, being necessary to evaluate larger and more homogeneous groups of patients with $\mathrm{CP}$ in future studies.

There are several means to diagnose bruxism activity, including questionnaires, clinical examination and observations of tooth wear, oral devices (occlusal splints) and portable electromyography ${ }^{38}$. Polysomnography in a sleep laboratory, however, is considered the most specific and accurate method ${ }^{38}$. All the studies cited in this review consider the presence of bruxism based on reports made by a third person and on clinical oral examination. However, according to Cash $^{39}$ and Vanderas and Manetas ${ }^{40}$, this method may be subjective and may generate misleading results since the parafunctional activity may have occurred without the caregiver's notice or when the caregiver was not present. Furthermore, the presence of wear facets may also indicate that bruxism occurred previously but may no longer be occurring at the time of the examination, or if it has developed recently, there may not have been enough wear to detect $\mathrm{it}^{40}$.

Individuals who have $\mathrm{CP}$ face many challenges that directly impact their quality of life. Although they are most commonly affected by bruxism, access to oral health care is a frequent problem for these individuals. Therefore, dentists must be considered as an integral part of the multidisciplinary team involved in the care of this group ${ }^{6}$, being able to identify and treat bruxism, as well as the oral signs and symptoms resulting from this parafunction.

Finally, it is worth noting that this review has the following limitations: search in only one language, no assessment of the quality of the studies, no assessment of the certainty of the evidence, and no analysis of the risk of bias. Therefore, it should not be taken as the highest level of evidence on the subject.

\section{Conclusion}

Based on the articles reviewed, it is concluded that bruxism in children and adolescents with cerebral palsy is a frequent oral condition; however, knowledge about the associated factors and risk factors for the occurrence of this problem in people with $\mathrm{CP}$ remains limited. Therefore, it is suggested that longitudinal studies with larger samples be carried out in order to clarify such aspects.

\section{REFERENCES}

1. Abanto J, Ortega AO, Raggio DP, Bönecker M, Mendes FM, Ciamponi AL. Impact of oral diseases and disorders on oralhealth-related quality of life of children with cerebral palsy. Spec Care Dentist. 2013;34(2):56-63. https://doi.org/10.1111/scd.12028

2. Ortega AOL, Santos MTBR, Mendes FM, Ciamponi AL. Association between anticonvulsant drugs and teeth-grinding in children and adolescents with cerebral palsy. J Oral Rehabil. 2014;41(9):653-8. https://doi.org/10.1111/joor.12185

3. Castinho LS, Abreu MHNG, Paula LF, Silva MES, Resende VLS. Oral health status among girls with developmental disabilities: a cluster analysis. Pesqui Bras Odontopediatr Clin Integr. 2017;17(1):e3403. http://dx.doi.org/10.4034/PBOCl.2017.171.23
4. Scholtes VA, Becher JG, Beelen A, Lankhorst GJ. Clinical assessment of spasticity in children with cerebral palsy: a critical review of available instruments. Dev Med Child Neurol. 2006;48(1):64-73 https://doi.org/10.1017/S0012162206000132

5. Ortega AOL, Guimarães AS, Ciamponi AL, Marie SKN. Frequency of parafunctional oral habits in patients with cerebral palsy. J Oral Rehabil. 2007;34(5):323-8. https://doi.org/10.1111/j.1365-2842.2006.01703.x

6. Dougherty NJ. A review of cerebral palsy for the oral health professional. Dent Clin North Am. 2009;53(2):329-38. https://doi.org/10.1016/j.cden.2008.12.001 
7. Levy H. General Dentistry for children with cerebral palsy. Cerebral Palsy. 2018;1-40

8. Lobbezoo F, Ahlberg J, Raphael KG, Wetselaar P, Glaros AG, Kato $T$, et al. International consensus on the assessment of bruxism: report of a work in progress. J Oral Rehabil. 2018;45(11):837-44. https://doi.org/10.1111/joor.12663

9. Pizzol KEDC, Carvalho JCDQ, Konishi F, Marcomini EMDS, Giusti JSM. Bruxismo na infância: fatores etiológicos e possíveis tratamentos. Rev Odontol UNESP. 2006;35(2):157-63.

10. Miamoto CB, Pereira LJ, Ramos-Jorge ML, Marques LS. Prevalence and predictive factors of sleep bruxism in children with and without cognitive impairment. Braz Oral Res. 2011;25(5):439-45. http://dx.doi.org/10.1590/S1806-83242011000500011

11. Gama E, Andrade AO, Campos RM. Bruxismo: uma revisão da literatura. Cienc Atual. 2013;1(1)

12. Cabral LC, Lopes AJC, Moura MB, Silva RR, Neto AJF, Simamoto Júnior CP. Bruxismo na infância: fatores etiológicos e possíveis fatores de risco. Rev Faculdade Odontol Lins. 2018;28(1):41-51. http://dx.doi.org/10.15600/2238-1236/fol.v28n1p41-51

13. Lindqvist B, Heijbel J. Bruxism in children with brain damage. Acta Odontol Scand. 1974;32(5):313-9. https://doi.org/10.3109/00016357409002554

14. Peres ACD, Ribeiro MO, Juliano Y, César MF, Santos RCDA. Occurrence of bruxism in a sample of Brazilian children with cerebral palsy. Spec Care Dentist. 2007;27(2):73-6. https://doi.org/10.1111/j.1754-4505.2007.tb00332.x

15. Elsayed RM, Hasanein BM, Sayyah HE, El-Auoty MM, Tharwat N, Belal TM. Sleep assessment of children with cerebral palsy: using validated sleep questionnaire. Ann Indian Acad Neurol. 2013;16(1):62-5

https://dx.doi.org/10.4103/0972-2327.107708

16. Santos MTBR, Ferreira MCD, Guaré RO, Guimarães AS, Ortega AL. Teeth grinding, oral motor performance and maximal bite force in cerebral palsy children. Spec Care Dentist. 2015;35(4):170-4. https://doi.org/10.1111/scd.12106

17. Souza VAF, Abreu MHNG, Resende VLS, Castilho LS. Factors associated with bruxism in children with developmental disabilities. Braz Oral Res. 2015;29(1):1-5.

https://doi.org/10.1590/1807-3107BOR-2015.vol29.0009

18. Edvinsson SE, Lundqvist LO. Prevalence of orofacial dysfunction in cerebral palsy and its association with gross motor function and manual ability. Dev Med Child Neurol. 2016:58(4):385-94 https://doi.org/10.1111/dmcn.12867

19. Rodríguez JPL, Ayala-Herrera JL, Muñoz-Gomez N, MartínezMartínez RE, Santos-Díaz MA, Olvera-Delgado JH, et al. Dental decay and oral findings in children and adolescents affected by different types of cerebral palsy: a comparative study. J Clin Pediatr Dent. 2018:42(1):62-6. https://doi.org/10.17796/1053-4628-42.1.11

20. Du RY, McGrath C, Yiu CK, King NM. Oral health in preschool children with cerebral palsy: a case-control community-based study. Int J Paediatr Dent. 2010;20(5):330-5. https://doi.org/10.1111/j.1365-263X.2010.01062.x

21. Smith BG, Knight JK. An index for measuring the wear of teeth. $\mathrm{Br}$ Dent J. 1984;156:435-8.

22. Genon P. Parafunções em crianças (diagnóstico). Quintessência. 1975;2(6):47-51.

23. Shaw L, Weatherill S, Smith A. Tooth wear in children: An investigation of etiological factors in children with cerebral palsy and gastroesophageal reflux. ASDC J Dent Child. 1998;65(6):484-6.
24. Durso BC, Beauclair BSD. Bruxismo noturno: aspectos clínicos e tratamento. Rev CROMG. 1998;4(2):90-3

25. Okeson JP. Fundamentos de oclusão e desordens temporomandibulares 2 ed. São Paulo: Artes Médicas, 1992; p. 449.

26. Zuanon ACC, Campos CG, Giro EM, Pansani CA. Bruxismo infantil. Odontol Clin. 1999;9:41-4.

27. Yip KHK, Chow TW, Chu FCS. Rehabilitating a patient with bruxism-associated tooth tissue loss: a literature review and case report. Gen Dent. 2003;51(1):70-4

28. Bahlis A, Rodrigues ML, Ferrari E. Bruxismo. Rev Odontol Cienc. 1999; 14(27):7-20

29. Ilovar S, Zolger D, Castrillon E, Car J, Huckvale K. Biofeedback for treatment of awake and sleep bruxism in adults: systematic review protocol. Syst Rev. 2014;3(1):1-9. https://doi.org/10.1186/2046-4053-3-42

30. Gomes CAFP, Politti F, Andrade DV, Sousa DFM, Herpich CM, Dibai-Filho AV, et al. Effects of massage therapy and occlusal splint therapy on mandibular range of motion in individuals with temporomandibular disorder: a randomized clinical trial. J Manipulative Physiol Ther. 2014;37(3):164-9. https://doi.org/10.1016/j.jmpt.2013.12.007

31. Amorim CS, Santo ASE, Sommer M, Marques AP. Effect of physical therapy in bruxism treatment: a systematic review. J Manipulative Physiol Ther. 2018;41(5):389-404. https://doi.org/10.1016/j.jmpt.2017.10.014

32. Beddis $H$, Pemberton M, Davies S. Sleep bruxism: an overview for clinicians. Br Dent J. 2018;225(6):497-501. https://doi.org/10.1038/sj.bdj.2018.757

33. Oliveira CAGR, Paula VAC, Portela MB, Primo LSG, Castro GF. Bruxism control in a child with cerebral palsy. ISRN Dent. 2011:2011:146915. https://doi.org/10.5402/2011/146915

34. Giannasi LC, Batista SRF, Matsui MY, Hardt CT, Gomes CP, Amorim $\mathrm{JBO}$, et al. Effect of a hyperbolide mastication apparatus for the treatment of severe sleep bruxism in a child with cerebral palsy: long-term follow-up. J Bodyw Mov Ther. 2013;18(2):62-7. https://doi.org/10.1016/j.jbmt.2013.05.009

35. Manzano FS, Granero LM, Masiero D. Treatment of muscle spasticity in patients with cerebral palsy using btx-a: a pilot study. Spec Care Dentist. 2004;24(4):235-9. https://doi.org/10.1111/j.1754-4505.2004.tb01699.x

36. Kesikburun S, Alaca R, Aras B, Tuğcu I, Tan AK. Botulinum toxin injection for bruxism associated with brain injury: case report. JRRD. 2014:4(51):661-4 https://doi.org/10.1682/jrrd.2013.10.0218

37. Cahlin BJ, Lindberg C, Dahlström L. Cerebral palsy and bruxism: effects of botulinum toxin injections - a randomized controlled trial. Clin Exp Dent Res. 2019;5:460-8. https://doi.org/10.1002/cre2.207

38. Carra MC, Huynh N, Lavigne G. Sleep bruxism: a comprehensive overview for the dental clinician interested in sleep medicine. Dent Clin North Am. 2012;56(2):387-13 https://doi.org/10.1016/j.cden.2012.01.003

39. Cash RC. Bruxism in children: review of the literature. J Pedod $1988 ; 12: 107-27$

40. Vanderas AP, Manetas KJ. Relationship between malocclusion and bruxism in children and adolescents: a review. Pediatr Dent. 1995:17:7-12. 